\title{
Pastoral Investigation on the Form and Usage of Local-Style Dwelling Houses in Jiarong Tibetan Traditional Village of Danba County
}

\section{-A Case Study of the Suopo Township in Danba County}

\author{
Bin Cheng, Libin Duan, Yangliu Fu \\ School of Civil Engineering and Architecture, Southwest University of Science and Technology, Mianyang, China \\ Email: duanlibin@mails.swust.edu.cn
}

How to cite this paper: Cheng, B., Duan, L.B. and Fu, Y.L. (2018) Pastoral Investigation on the Form and Usage of Local-Style Dwelling Houses in Jiarong Tibetan Traditional Village of Danba County-A Case Study of the Suopo Township in Danba County. Journal of Building Construction and Planning Research, 6, 52-70.

https://doi.org/10.4236/jbcpr.2018.62004

Received: March 26, 2018

Accepted: June 25, 2018

Published: June 28, 2018

Copyright ( $) 2018$ by authors and Scientific Research Publishing Inc. This work is licensed under the Creative Commons Attribution International License (CC BY 4.0).

http://creativecommons.org/licenses/by/4.0/

(c) (i) Open Access

\begin{abstract}
Under the dual background of rapid development and urbanization, the research is of practical significance for the construction and development of new rural harmonious society on the traditional villages, residential forms and ways of using. The purpose of this study is to learn the characteristics of the local residential forms and their usage, reveal the relationship between these characteristics and villagers' lifestyles, and grasp the villagers' evaluation of the satisfaction on living space, by the investigation of 168 questionnaires, 16 families in-depth interviews and survey mapping in the $\mathrm{W}, \mathrm{Y}$ and $\mathrm{Z}$ villages of Suopo Township, Danba County, Sichuan Province. The resulted showed that: 1) Residents have obvious uniform features, mostly 3 - 5 layers of single-family residences, mostly in the area of $400-500 \mathrm{~m}^{2}$. The height of the house and the rooms has a relatively fixed modulus. 2) In the survey of the usage of local dwelling houses, it was found that farmers have a fixed model for the use of residential buildings. Most of the living activities are gathered in their own courtyards, and the utilization of the living room is usually limited. The floors above the second floor often have the terrace formed by the retreat to dry the food. There are often more bedrooms for spare, more than $90 \%$ of the family of four or more have two or more living rooms. 3) The residential area is embodied in both horizontal and vertical directions: the first floor of the indoor room from the courtyard to the dining room has the property of semi-open and semi-private space, and it is the main place for neighborhood interaction; and the rooms of the second and above are more private. 4) In the long process of life, the form and usage of houses will change with the changes of external factors. The traditional dwelling houses will be built or renovated, accounting for about $36 \%$ of the total amount surveyed.
\end{abstract}




\section{Keywords}

Suopo Township in Danba, Jiarong Tibetan, Pastoral Investigation, Residential Form, Usage

\section{Introduction}

Danba County, located in the eastern part of Ganzi State in western Sichuan Province, is the core settlement of the Jiarong Tibetan (Figure 1). Under the influence of Chinese urbanization wave and foreign culture, the living environment of the local villagers has changed dramatically, the spatial morphology of traditional villages and the lifestyle of villagers have begun to change. If the living environment of the villagers did not change with their needs, mentality and role transformation, all kinds of social contradictions would come out. Therefore, it is of practical significance for the construction of a harmonious society to study the spatial structure form of dwellings, usage and human behavior changes with time and environment. In addition, it provides corresponding design strategies for the transformation of residential environment in Jiarong Tibetan area.

In recent years, there have been some empirical studies on the residential space of some rural areas in China. Zhang Qing [1] attempted to use anthropology, focusing on peasants' life practices and habits and explored the transformation of the residential form of rural areas from villages to peasants' concentrated residential areas in the process of urbanization. Li Bo [2] conducted a study on the sustainability of the residential space environment of rural communities in Changyuan County, Henan Province. And it analyzed from two aspects of lifestyle and residential space environment in detail. In view of the specific geographical conditions in Changyuan County, it explores the sustainable development strategies of residential space environment in rural community. Hu Peng [3] based on the investigation of the current situation of the new rural residential area in western Anhui Province. From the view of architecture, it guided by the theory of residential design and combined with farmers living problems to analysis and research farmers' residential design. Finally, it can form the theory and method suitable for residential design in the western of Anhui province. All of these provide reference for the research ideas of this thesis. However, in other developed countries, there is relatively little research on the residential space in rural areas due to the small difference in living standard between rural and urban areas. Most of the theoretical results are focused on the study of urban residential space [4]-[10]. Basically, it is still to study the relationship between living space and people. The concepts and principles of human-economic-social-natural equality, complementarity and respect formed by these modes of living space can also be used in the study of rural residential space. On the basis of previous researches, we found that residential space research was still in the initial stage of exploration. And the mechanism has not been fully understood. Therefore, we 


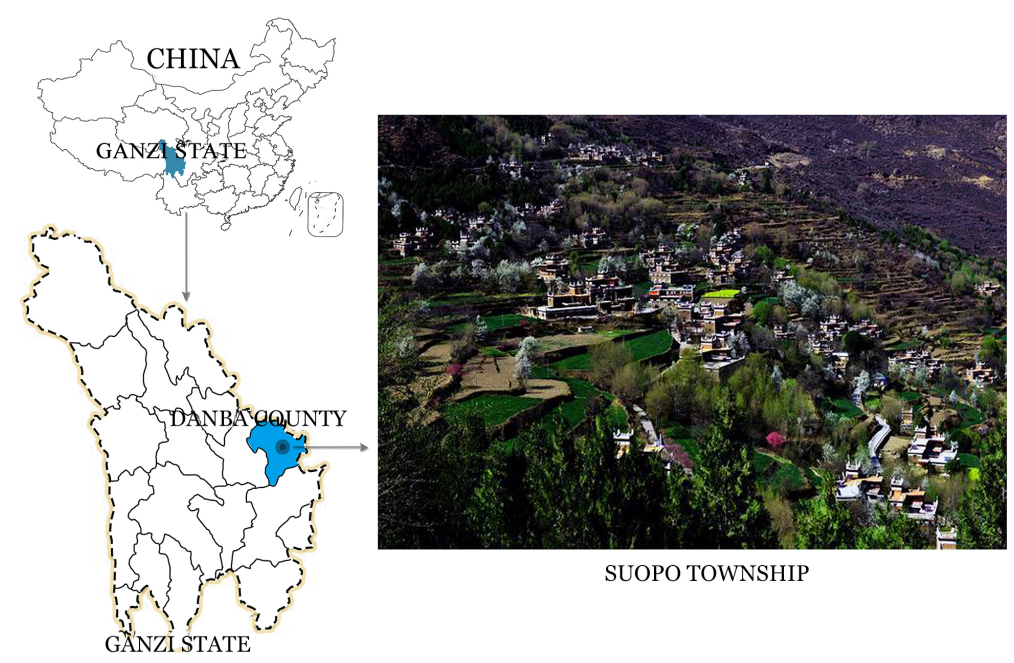

Figure 1. The location of Suopo Township.

would like to make some new attempts in some traditional settlements for exploring this issue further and comparing with the research results of new rural areas in other regions. In this study, we selected three villages which are more complete traditional style, fewer newly-built dwelling houses and have a large-scale traditional houses as the research object in Suopo Township, Danba County, Ganzi State, Sichuan. And it aimed to grasp the structure and form of residential houses in the traditional villages of Jiarong Tibetan and the way of daily villagers' use of dwelling houses. Through field mapping, questionnaire survey and other forms, we can deeply understand the structure and form of the local stone house and grasp the real living habits and lifestyles of the villagers. It provides an example for the empirical study of the residential space for the traditional settlements of ethnic minorities.

\section{General Situations of Research Area}

\subsection{The Present Situation of Danba Traditional Dwellings}

Danba is the high mountainous area of Minshan-Qionglai mountains, located at the junction of Han and Tibetan. And its special geographical location and historical development have created the characteristics of Tibetan settlements and multi-cultural buildings in this area. The Dadu River runs through the entire territory from north to south and cuts mountains. The three-dimensional landscape is remarkable. There are numerous peaks and deep valleys in the territory. Due to the influence of the monsoon climate of the Tibetan Plateau, the climate is typical of a three-dimensional climate, and it has the climate characteristics of "one mountain of the four seasons and different weather". Its special conditions regarding geography, geology, and climate determine the uniqueness of traditional structure, form, and functional space. It forms a traditional residential building [11] with stone masonry, and has a slightly defensive color and a high research value. A large number of dwelling houses are maintained and repaired 
by the villagers, and the traditional style and features are continued, and the quality of the houses is better. The size of the new residential area has gradually increased, but the layout has changed little. Most of the traditional materials and construction technology are still continued, and the decorative style is roughly the same. For the study of the traditional dwellings in Jiarong Tibetan area, there are more research results in the specific settlement form [12] [13] [14], single buildings [15] [16] [17] [18], construction mode [19] [20], architectural decoration and national belief. However, under the influence of China's urbanization wave and foreign culture, great changes have taken place in China's rural society in recent years, and the spatial morphology of traditional village and the lifestyle of villages have begun to change. In order to adapt to this change, villagers have also started to renovate their homes by using alterations, additions and other means. Many scholars have also begun to pay attention to the issue of residential renewal. Most of them focus on the protection of traditional residential heritage to propose residential development strategies and update from different ideas and directions [21] [22] [23]. There is also an update on the construction technology in terms of structure, technical means, etc. [24].

\subsection{The Function and Form of Danba Residence Renewal}

Along with the development of tourism, the villagers' living ideas and demands are changing. On the one hand, villagers get better and more comfortable living environment. On the other hand, they begin to rebuild or expand their own houses in order to gain greater economic benefits. Therefore, the function of Danba dwelling houses is becoming more complicated and functional. In terms of function, the number of bedrooms and restrooms has obviously increased. The demand frequency of the living room has increased, and its position has been gradually extroverted. In terms of form, there are more cases about additional buildings attached to buildings. And more auxiliary buildings have been built on the second floor (the first for livestock houses), the terraces of the third and the fourth. The overall form of dwellings is gradually transformed from the "L" type-"U" type-"O" type, and finally it shows the plane of the Patio-style building on the second floor. But whether these dwellings update changes are adapted to their lifestyle, whether the villagers' living environment can be transformed as their needs, psychology and roles change, and the above problems need to be investigated and researched. The reasonable comfort of residential buildings contributes to the construction of a harmonious society [25] [26]. Therefore, it has certain practical significance for the research of villagers' living environment and traditional dwelling houses.

\subsection{Problems in the Investigation and Settlement of Danba Residences}

In our previous research, there has been an investigation and research on the stone masonry houses of Danba Jiarong Tibetan [27], which has a basic understanding of Danba dwellings. This study will further research the lifestyle and 
routine behavior of local villagers to explore the space form of their traditional dwellings, understand the characteristics about form and usage of local Jiarong Tibetan dwellings, and reveal the relationship between these characteristics and villagers' lifestyles and daily behaviors. Finally, we can grasp the villagers' satisfaction evaluation status of traditional residential usage.

\section{Methodology}

Survey research has been widely applied in various disciplines. The survey is conducted in two ways: investigation and statistical analysis. The purpose is to conduct in-depth investigation and to obtain a large amount of basic data on the form, usage and lifestyle of local villagers. A detailed survey of this work is as follows:

\subsection{Survey Method}

\subsubsection{Questionnaire Investigation}

The questionnaire survey about villagers' lifestyle and dwelling houses in July 2017 was carried out. And the questionnaire was designed through consulting a large number of literatures, summarizing and extensive discussion. The main object of the investigation was local villagers and local administrators. The content of the investigation is divided into two parts: the basic situation of the individual family and the methods of residential usage. The basic situation of the individual family mainly involves the family population structure, quantity and the basic personal information of respondents. The population variables of respondents considered include gender, age, occupation type and educational level (as shown in Table 1). The methods of residential usage include: residential years and forms, spatial patterns, the number and use of various types of rooms, indoor and outdoor behaviors of villagers, neighborhood interaction, satisfaction of housing, etc. A total of 200 questionnaires were issued and 168 valid questionnaires were collected.

Table 1. Investigate demographic variables.

\begin{tabular}{|c|c|c|c|c|c|}
\hline Age & & Educational Level & & Occupation & \\
\hline under 20 & 34 & Non-educated & 43 & student & 32 \\
\hline $20-40$ & 23 & Elementary & 16 & teacher & 9 \\
\hline $40-60$ & 48 & Intermediate & 38 & worker & 34 \\
\hline \multirow[t]{4}{*}{ over 60} & 53 & High School & 48 & farmer & 49 \\
\hline & & Undergraduate Degree & 23 & administration staff & 21 \\
\hline & & Postgraduate Degree & 0 & other & 23 \\
\hline & & Other & 0 & & \\
\hline Total & 168 & & 168 & & 168 \\
\hline
\end{tabular}




\subsubsection{Residential Field Mapping}

Based on the issuance of questionnaires, there was a general understanding of situation, range, quality and quantity about residences of the entire Suopo Township. We selected the more representative $\mathrm{W}, \mathrm{Y}, \mathrm{Z}$ three villages, and summarized the years and conditions of dwelling houses of these three villages. According to the construction period, the dwelling houses were divided into 4 categories: before 1990s, 1990-2000s, 2000-2010s, and after 2010s. And selected the more representative dwellings in each generation, striving for the largest range of different combinations of dwelling spaces. Finally, 16 residential houses were selected for field mapping, obtaining detailed housing layout and room usage.

\subsection{Statistical Analysis}

By means of mathematical method, the percentage quantitative analysis was used to quantize the questionnaire, and the statistical analysis was carried out by using the quantitative data. Aspects of statistical data were used from the usage of various rooms and activity places, the number of rooms. And the percentage share was counted. It is necessary to grasp the proportion of dwelling houses in terms of the status quo, spatial forms and usage, and to find out the obvious characteristics of common trends in the form and usage of traditional dwelling houses.

\section{Analysis of Samples}

\subsection{Residential Form}

\subsubsection{General Situation}

The dwelling houses currently used for living are mainly built after 1990, accounting for $63.2 \%$ of the total. Due to the tourism and economic development in Danba County, the local government began to pay attention to the protection and development of ethnic villages. The construction of local villagers can give corresponding government subsidies. Therefore, there are a lot of newly built stone dwelling houses at this period. Later, due to the improvement of economic conditions and the further development of tourism, part of dwelling houses have been reconstructed. There are three main types of reconstruction: 1) Interior and exterior decoration 2) Stamped roof houses 3) building attached housing. Most of the old houses in the earlier years of the last century were abandoned or dismantled. And there are few existing ones, accounting for about $12.7 \%$ of the total. Some of which have built alongside new houses (Figure 2). Most of the other newer homes were renovated after 1990.

\subsubsection{Main Characteristics of Residential Form}

The surveyed dwellings are all stone-built independent houses, mostly for 4 or 5 floors. The 4 floors accounts for $37.8 \%$ of the total survey and the 5 floors accounts for $52.4 \%$. Within the scope of the investigation, there is only one store with ordinary residential functions in the first floor buildings. There are fewer 


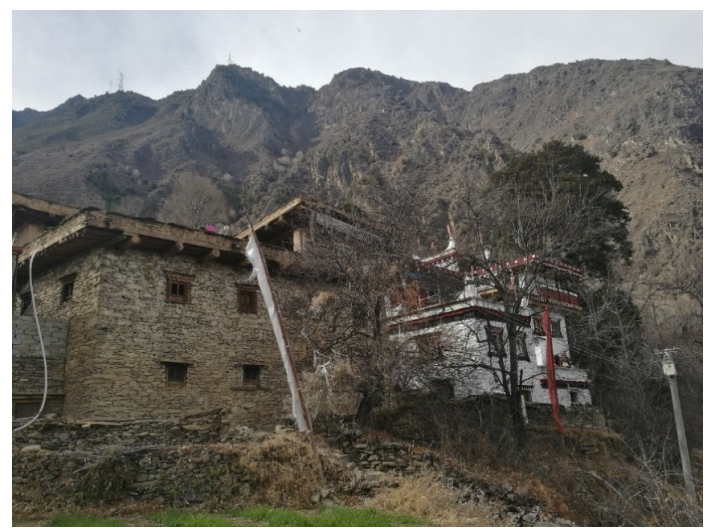

Figure 2. New house was built beside old houses.

traditional residential buildings of 2 or 3 floors, accounting for about $9 \%$ of the total. There are no more than 6 floors and higher residential form (Figure 3). This spatial structure is actually determined by the local villagers' production lifestyle and religious culture. Tibetans living in Danba retain their traditional ways of farming and livestock breeding, so their houses need some space to store grass and livestock. In their religious culture, there are different meanings and functions at every floor of Jiarong Tibetan dwellings [28]: the first floor (the ground floor) "rewa"-the place of livestock; the second floor "gahuayin"-where people live; the third floor "bazan"-a place for hospitality; the fourth floor "gadi" - the place of drying crops; the fifth floor "zuori"- the place of burning incense to bless. Therefore, Jiarong Tibetan dwellings are mostly five floors. But now, many houses built four-story simplify later, and the tower of burning incense built on the fourth floor of the building roof. In the residential environment, the spatial relationship that people living in the middle floor, the bottom floor of livestock, and the top floor of the scripture hall is also a reflection of their Tibetan Buddhist belief in the status of God, man and livestock.

The residential building area is larger than that of the city, accounting for $28.5 \%$ of the total area of above $600 \mathrm{~m}^{2}, 63.2 \%$ of the $400-600 \mathrm{~m}^{2}$. And less than $400 \mathrm{~m}^{2}$, accounting for about $8.3 \%$ of the total.

Through surveying and mapping, it is found that the stone masonry dwelling houses built by the Jiarong Tibetans are generally square in shape and compact in plane, with the aspect ratio of about 1.1-1.3. The height of indoor is low, and it is kept between 2.3 and $2.5 \mathrm{~m}$. Using the terrain elevation ingeniously, the livestock house is set up at the bottom, with its own independent entrance. The second floor is mainly used for daily diet, meeting and living. And the third or fourth floors are mainly composed of rooms and terraces, which are used for living, storing and drying food. There are the space for wooden panels spliced out in the third or fourth floors, forming the overhang balcony for walkways and storage. There is a semi-open room or "lese"-the tower of burning incense, used for simmering Sang ceremony in the early morning. It is a real photo of the typical Jiarong Tibetan dwelling houses, reflecting the general characteristics of the local residential forms (Figure 4). 


\begin{tabular}{|l|l|l|}
\hline Number & \multicolumn{1}{|c|}{ Details } \\
\hline 1 & $\begin{array}{l}\text { The 2-storey dwellings are less. The internal } \\
\text { space forms close to the urban housing, } \\
\text { simplifying the livestock and sacrificial space, } \\
\text { only for residential use. }\end{array}$ \\
\hline 3 & $\begin{array}{l}\text { The form of the 3-storey dwellings is a } \\
\text { simplification of traditional Jiarong Tibetan } \\
\text { dwellings: the first floor (the ground } \\
\text { floor)-livestock houses; the second } \\
\text { floor-living space; the third floor-terrace. }\end{array}$ \\
\hline 2 & $\begin{array}{l}\text { The 4-storey dwellings are common, which is a } \\
\text { simplified version of the traditional 5-storey } \\
\text { dwellings. The tower of burning incense is built } \\
\text { on the fourth storey roof. }\end{array}$ \\
\hline
\end{tabular}

Figure 3. Typical dwellings schematic.

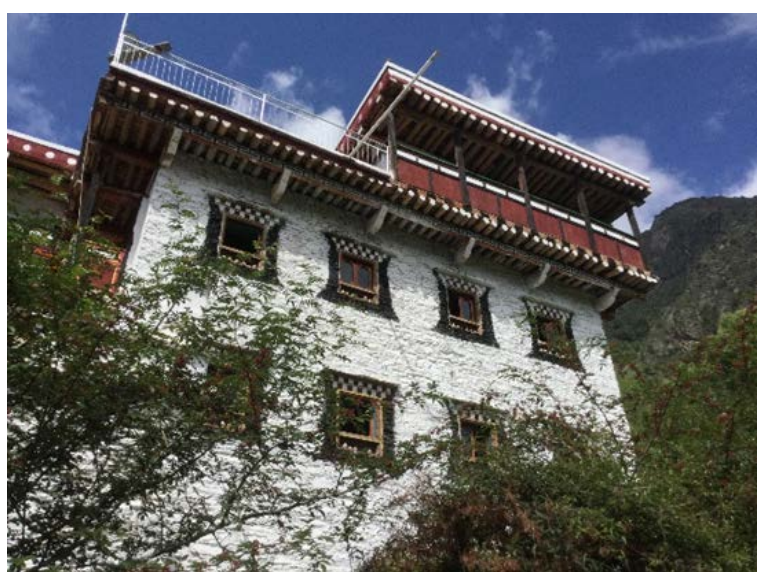

Figure 4. The typical Jiarong Tibetan dwelling buildings.

Unlike urban dwellings, they have their own outdoor space by their own houses enclosed, namely yard. The courtyard with cement plaster is spacious, smooth and wide field of vision. Farmers rarely plant trees or other plants in their courtyards. And plants are planted in the private plots around residential areas.

There are also many ways to define the field of your own land. Some encloses with houses or fence; some of them elevate the floor to distinguish the courtyard 
and road by height difference; others directly used wood sticks to insert into the fence as a dividing line.

\subsection{Residential Use}

\subsubsection{Spatial Patterns and Domain Levels}

Through the interviews and surveys of 16 farmers and the mapping of the residences, we get the detailed information about the residential form and their usage. The following is a summary of the more representative parts about these 16 households (Table 2).

1) Appearance Form. The residential forms are mainly $4-5$ layers. And they are stone structures. The upper part of the wall is small, the lower part is large. And it is contracted from the outside, and the interior wall is kept vertical. According to surveying and mapping, the external wall is contracted 4 - 7 degrees. The lower part is $660 \mathrm{~mm}$ at the widest, and the upper part is about $420 \mathrm{~mm}$ at the narrowest.

2) Spatial pattern. In the location and orientation of dwellings, they can choose the place which faces towards the sun. The dwellings are built on the back of the mountain and the front of water. However, for the holding of a ritual such as burning incense or other ceremonies, they can choose from area near the Mo'erduo Mountain, and toward the direction of the mountain. So residential orientation is generally determined by mountain potential, and there is no definite north or south direction. In the internal space model, the general firewood room and tool rooms are arranged by the interior, the livestock house by outside. And there is a separate entrance in the first floor of the layout. The relative second floor space of the livestock room is usually provided with half open space for feed processing. And it can also be used for the storage of motorcycle and other means of transportation. In the second floor, kitchen and restrooms are mostly arranged by the interior independently, and near the entrance door. The living room, the bedroom and the staircase are arranged on the inside side of the whole house. Most of the staircases also have storage functions. The third and fourth floors are made of the bedrooms and the terraces. The bedroom is arranged in the interior, generally by the outside with wooden panels spliced out, forming the overhang balcony for walkways and storage. There is a semi-open room or "lese"- the tower of burning incense, used for sacrifices.

3) Spatial hierarchy sequence. In the horizontal direction from outdoor to indoor, we should experience the following sequence: the road-the courtyard gate-the courtyard-the front door of the house-the interior. In space, we are going through a process of changes: open space-semi-open space-semi-private space-private space. The courtyard, the doorway and the restaurant are semi-open and semi-private areas. In general, the courtyard gates often open. People don't have to take off your shoes when they enter. Neighbors often visit and chat in the yard, the doorway and the restaurant. In a certain extent, it also protects the owner's private space. In the vertical direction, the first floor is a place for the whole family dining and neighborhood interactions such as the living room, 
Table 2. Typical basic situation of interview residents.

\begin{tabular}{ccccccccc}
\hline Number & $\begin{array}{c}\text { Construction } \\
\text { Date (year) }\end{array}$ & building area $\left(\mathrm{m}^{2}\right)$ & $\begin{array}{c}\text { courtyard area } \\
\left(\mathrm{m}^{2}\right)\end{array}$ & layers & bedrooms & $\begin{array}{c}\text { Utility } \\
\text { rooms }\end{array}$ & $\begin{array}{c}\text { courtyard function } \\
\text { Numbers of } \\
\text { family }\end{array}$ \\
\hline A & 2004 & 496 & 43 & 5 & 5 & 1 & $\begin{array}{c}\text { Put on motorcycle, play, } \\
\text { laundry, neighbors chatting }\end{array}$ \\
B & 2006 & 735 & 42 & 5 & 6 & 4 & neighbors chatting, play \\
C & 1998 & 465 & 23 & 5 & 4 & 2 & $\begin{array}{c}\text { laundry, neighbors chatting, } \\
\text { do farm work } \\
\text { traffic space }\end{array}$ \\
D & 1993 & 265 & 12 & 4 & 3 & 1 & traffic space \\
E & 2001 & 346 & 18 & 4 & 4 & 2 & 3 \\
\hline
\end{tabular}

dining room, kitchen, etc. The second floor of bedrooms is a private field, which is generally not allowed by strangers. The first and second floors are connected by the staircase, and it has realized the transformation of semi-open and semi-private areas to private areas in human psychology.

\subsubsection{Various Types of Room Usage}

1) Eating habits. The kitchen and the courtyard outside the kitchen can be used as a place of eating. There is a large table near the firewood stove in the kitchen, which can be used for 8 - 9 people to eat at the same time. At noon, if children went to school and young adults did not come back to farming, the old man would eat lunch with sunbathing at random in the yard. Or, if one or two young people came back after they finished their farms, they would sit at the courtyard and take a rest while eating lunch at random. At night, when the whole family comes together or has guests to visit, they will sit around the table in the kitchen to eat dinner, which will create a happy atmosphere of reunion.

2) The use of the living room. The usual use of the living room, the elderly are relatively more than young people. Evening is relatively more than during the day. The neighborhood chatting is usually at the door courtyard or restaurant. The use of the living room will become more frequent only when important guests or relatives and friends arrive during the festival.

3) Storage room usage. Almost every floor has storage space for debris. And stairs are often used as storage spaces. Due to the different positions, there are also differences in the items stored. For example, the storage room that next to a livestock house is used to store labor tools, feed, pesticides and so on. The storage room of the second floor is generally semi-open, and it is used to store small labor machines, transportation tools and so on. The storage room that next to the restroom is used to store laundry basins, washboard etc.

4) The use of the yard. The use of the yard and the richness of its activities depend on two factors: first, the size of the yard; Second, the space type of the yard. In general, the larger the size of the yard, the richer activity there is. The half-open courtyard surrounded by two or three sides is better than the closed courtyard surrounded by four sides, which is more beneficial to the organization 
of human interaction and activities.

\subsubsection{The Place of Activity Usage (Figure 5)}

1) The place of watching TV

$78.3 \%$ of the respondents chose to watch TV in the living room, while only $19.2 \%$ in the bedroom. The number of people who choose kitchens and restaurants is less at only $2.5 \%$. The survey found that in farmers' homes, most of TVs are placed in the living room. However, a small number of elderly people prefer the bed cabinets of their bedrooms.

2) The place of wedding

Most of villagers do weddings in their own home or yard, and the respondents account for about $81.7 \%$. In addition, due to more visitors, their own home cannot afford. $11.3 \%$ of the surrounding public space should be occupied. Only about $7 \%$ of farmers choose a restaurant for weddings in the county.

3) The place of storing food and farm tools

The places where food and farm tools are stored are the ground floor (the first floor), the floors and the attached houses. Most of villagers chose the half-open rooms beside the balcony of the third and fourth floors to serve as food storage sites, accounting for $90.7 \%$ of the total. Only a small number of villagers will store grains in the storerooms or the attached houses next to the second-floor kitchen. The storage of agricultural tools is about $57.7 \%$ of villagers in the semi-open space of the second floor of the processing feed or the second-floor attached houses. $28.5 \%$ of the storage room on the ground floor (the first floor). Most of the rest are in the stairway.

\subsubsection{The Relationship between the Demand of Room Quantity and Family Structure}

1) The relationship between the demand of bedroom quantity and family structure

It reflects the relationship between the family structure and the demand of bedroom quantity (Figure 6). More than 65\% of families with "couple plus children" have five or more bedrooms, and others with four bedrooms accounted for about 28\%. "Couples and children plus one side of the elderly"-family is also the largest choice of 5 bedrooms. In addition, most of the family of "Couples and children plus double sides of the elderly" chose six bedrooms and above, accounting for $65 \%$, and $30 \%$ of five bedrooms. With the increase of family population, the demand for bedroom quantity has also increased significantly. Compared with other rural areas, the housing area of the Jiarong Tibetan region in Danba is larger. And the number of dwelling houses is much more than other rural areas. Moreover, in recent years, with the development of local tourism, many dwelling houses have been built and renovated. And the guest room for tourists has increased. The positive correlation between the number of bedrooms and family structure is getting less and less.

2) The relationship between the demand of living rooms quantity and family structure 
It reflects the relationship between the family structure and the demand of living room quantity (Figure 7). Among them, more than $67 \%$ of the families with the "Couples plus children" chose one living room, others with two living rooms accounted for 25\%. "Couples and children plus one side of the elderly" and "Couples and children plus double sides of the elderly"-families both choose two living rooms that account for more than $70 \%$, and about $30 \%$ of them choose more than two. It can be seen that different types of families have different requirements for the living room quantity. The three generations of families who live together need 1 - 2 living rooms, mainly 2 rooms.

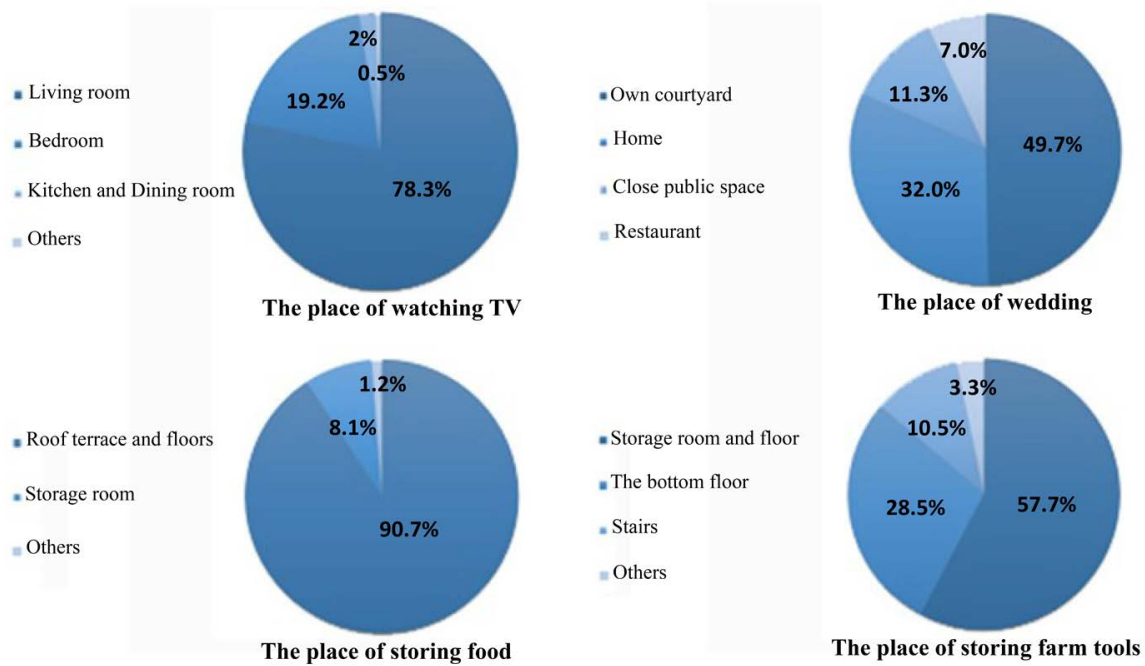

Figure 5. The place of Activity usage.

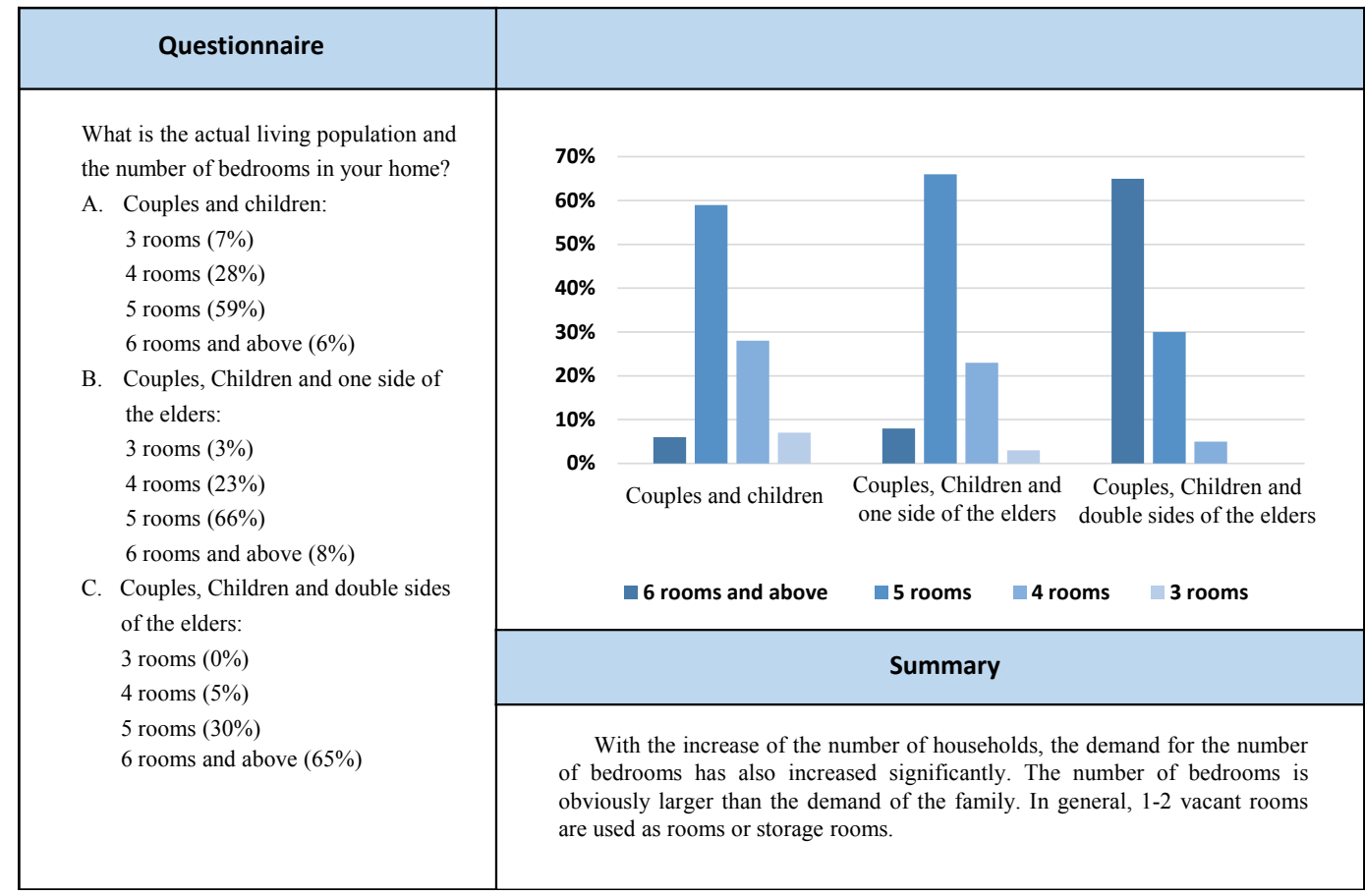

Figure 6. The relationship between the number of bedrooms and the number of family's needs. 


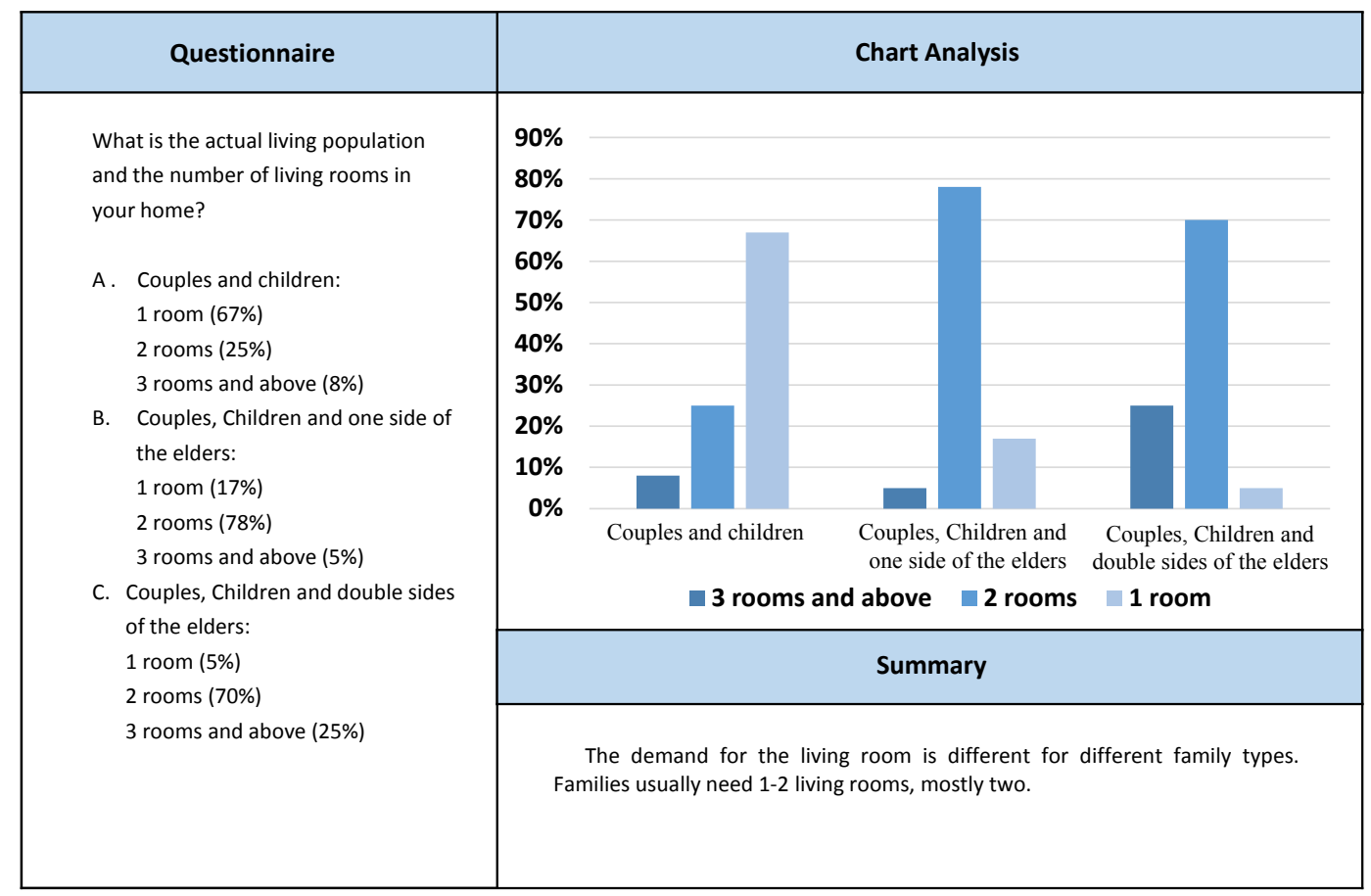

Figure 7. The relationship between the number of living rooms and the number of family's needs.

\subsection{The Cases of the Change Process of Residential Form and Usage}

The White Horse House was built in 1998 and was rebuilt in 2005, 2010 and 2013, as shown in the current housing usage situation (Figure 8). In addition to the owner's living, some rooms are rented to tourists, which are relatively isolated from their owners' living places. The old couples had one son and one daughter. And the family of four people lived in the old house that built in 1998 . At that time, the gate was on the east side of residential courtyard, the restroom was on the west side of the second-floor. And the north side of the second-floor was a living room and a bedroom. The living room next to the mill.

In 2005, in order to improve family living conditions, the hostess ran a small shop. In the southeast of the original old house, a small shop and the storage room were built. The restroom was moved from the west to the east side, and the gate was located on the southern of the courtyard. The original mill was changed into the utility room, and the new mill was moved to the original restroom. In 2010, for the elder son's marriage, they built a new house on the western of the old house. There were two bedrooms, two restrooms, one living room and one storage room in the new house. Turned the original mill into a daily hall. The new mill moved to the original utility room. The whole family shared the southern kitchen and the new mill. In 2013, the son and his wife had children, and then moved to the county town to live. They only came back from the holidays, therefore, their bedroom was moved from the second floor to the smaller bedroom on the third floor. As a result, the old couples added two bedrooms on the third-floor for their families to stay home on holidays. The west-side rooms that 
originally rebuilt on the second floor were used to supply the lease and provide B \& B services, due to the development of local tourism. Compared with 1998, the usage of the remaining floor rooms did not change much.

From the change process of the form and usage of the dwellings (Figure 9), it is found that:

1) The newly built house has a certain inheritance with the old house on the functional layout, maintaining the interrelationship between them. First of all, it inherited the old house deep in depth. There is a hall connected with the old house. Second, the young couple and old couple shared a kitchen and ate together. Although the new house is connected with the old house, but it has a degree of spatial independence and it is separated by doors. It shows that after the son gets married, he establishes his own family and maintains independence with his parents.

2) As can be seen from the changing process of the White Horse House, the events will have a certain impact on the form of dwellings, such as "the awakening of villagers' economic consciousness", "son's marriage", "birth of a child", "son independent portal" and so on. There is a certain connection between the form and usage of dwellings and the number of the family structure. People and the living environment are in the dynamic changes to achieve the corresponding balance. And with the development of times, the rise of rural tourism will also bring great influence to local dwellings.
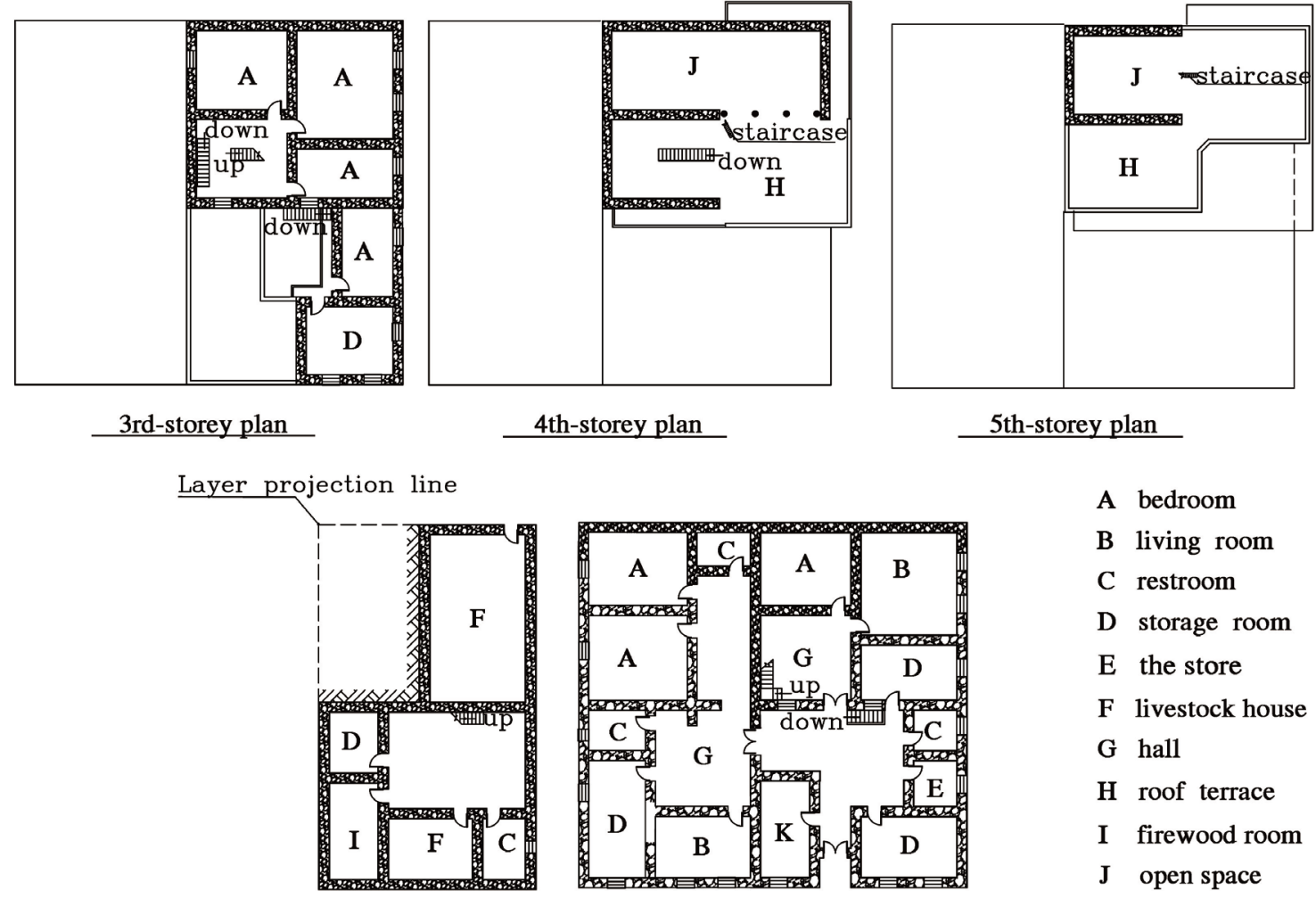
A bedroom
B living room
C restroom
D storage room
E the store
F livestock house
G hall
$\mathbf{H}$ roof terrace
I firewood room
J open space
$\mathrm{K}$ kitchen

1st-storey plan

2nd-storey plan

Figure 8. The situation of current dwelling building usage. 


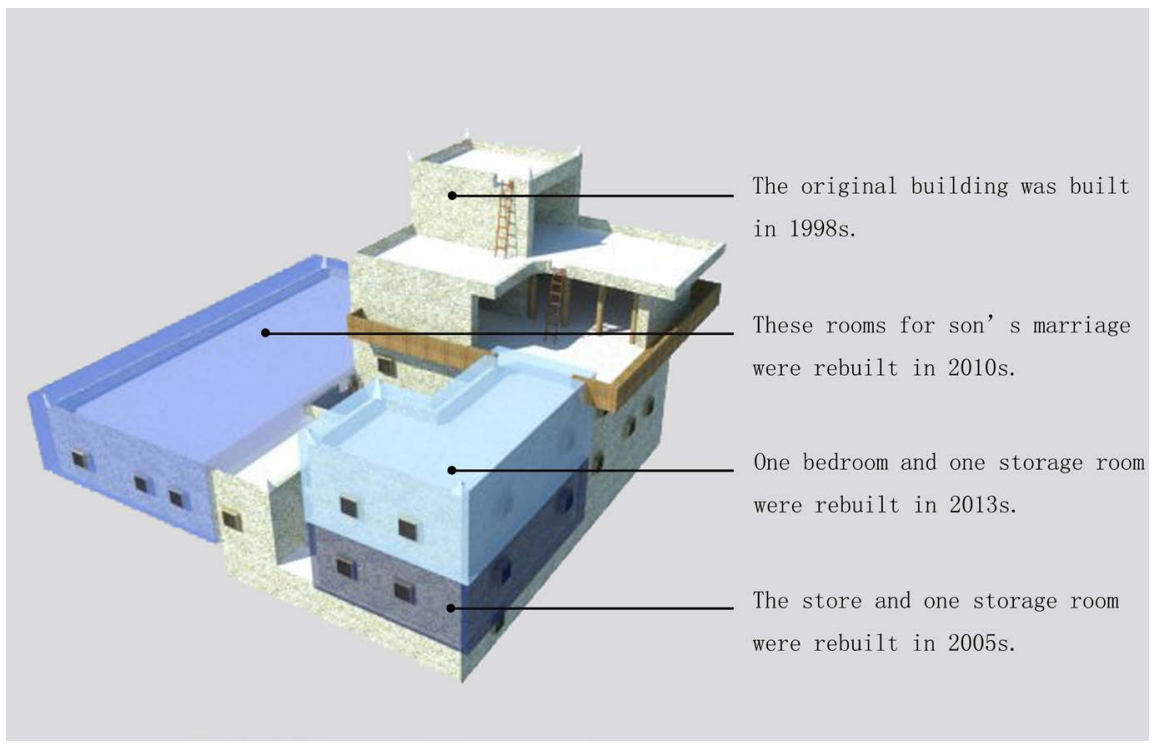

Figure 9. The change process of the White Horse House.

\section{Discussion}

According to the fifth census data, the total population of Suopo Township in Danba County is about 3 million, and the number of households is about 670. In this survey, a total of 200 questionnaires were issued and 178 valid questionnaires were recovered. The scope of investigation accounted for about $29.8 \%$ of the total number of households in the whole Suopo Township, so the author thinks that the proportion of the survey data can be representative. Based on the exploration and general understanding of the status quo of traditional dwelling houses in the entire area of Suopo Township, we selected three villages with more representative dwelling houses and summarized the conditions of dwelling houses of these three villages. According to the construction period, the dwelling houses were divided into 4 categories: before 1990s, 1990-2000s, 2000-2010s, and after 2010s. In each category, we select the more representative traditional dwellings for surveying and mapping, striving for the largest range of different combinations of dwelling spaces and the usage of different places and rooms. Therefore, the 16 traditional dwellings in detailed surveying and mapping have a certain representative significance for the Jiarong Tibetan traditional dwellings in Suopo Township, Danba County. The percentage analysis method is used to analyze. And the effective data of the questionnaire are processed and analyzed to find the obvious commonness and trend of traditional residential form and usage pattern. This method is more scientific and intuitive.

In 2017, Sichuan Province promulgated the "Measures for the management of rural housing construction in Sichuan Province" [29]. It has put forward the related management methods on the housing construction of the original homestead, construction and renovation of old residents, the old rural housing security management issues and so on. For example, "If a dwelling house is reconstructed or expanded, rural construction workers or construction units must not 
endanger the safety of the original building structure", "Rural housing contractors should assist villagers in selecting qualified building materials. Encourage the use of green building materials" and so on. It regulates the problem of rural housing construction to a large extent, and prevents the problem occurred such as private building, disorderly construction, the impact of the feature of the whole township and so on. It also indirectly constrains the wanton expansion of the house volume and protects the form of the traditional dwellings. The quality of the houses has been strictly regulated. And the technology, safety and earthquake resistance have been gradually improved. It also greatly protects the life and property safety of local residents. In terms of quantity, it prevents the influence of wanton construction and self-construction on the feature of the whole local village. In addition, the proportion of family population structure is different, and it may also affect the form of dwellings to a certain extent. For example, the family has one son, one daughter or two sons. It may have an influence on the residential housing structure. The former may be asymmetrical on the third floor, and the latter is symmetrical. The building area of the former may be less than the latter. In this regard, further research is needed to demonstrate the relationship between the family population structure and the form of dwellings.

For example, "If a dwelling house is reconstructed or expanded, rural construction workers or construction units may not endanger the safety of the original building structure", "Rural housing contractors should assist villagers in selecting qualified building materials. Encourage the use of green building materials" and so on.

\section{Conclusions}

The conclusions of this study are as follows:

1) Through the study on the residential form of Jiarong Tibetan, it is found that residents in $\mathrm{W}, \mathrm{Y}, \mathrm{Z}$ villages have obvious uniform features. The main factors affecting the form of the Jiarong Tibetan dwellings include the topographic conditions of the homestead, the number and structure of the family population and the economic conditions, etc.

2) In the survey of the usage of local dwellings, it was found that farmers have a fixed model for the use of residential buildings. And the residential area is embodied in both horizontal and vertical directions.

3) In the long process of life, the form and use of dwellings also change constantly with some major events (births, marriages, etc.). The lifestyle can be continued, and the mutual penetration of people and the environment can be achieved a dynamic balance.

\section{Acknowledgements}

From the beginning of the investigation to the completion of writing, this research lasted nearly four months. Thanks are due to my colleagues for assistance with the experiments and to research group for valuable discussion. This work is 
supported by Southwest University of Science and Technology PhD Fund: Research on green renewal of stone-built dwellings in Sichuan Tibetan Area (grant no.16ZX7133).

\section{References}

[1] Zhang, Q. (2008) The Change of Rural Living Patterns in the Process of Urbanization. East China Normal University, Wuhan.

http://www.cnki.net $/ \mathrm{kcms} /$ detail/detail.aspx?dbname $=$ CMFD2008\&filename $=20081$ $\underline{\text { 46759.nh }}$

[2] Li, B. (2012) Research on Sustainability of Living Space Environment for Rural Communities in Changyuan County, Henan Province. Xi'an University of Architecture and Technology, Xi'an.

http://www.cnki.net/kcms/detail/detail.aspx?dbname=CMFD2013\&filename $=10120$ $\underline{45603 . n h}$

[3] Hu, P. (2015) Optimal Design Research for Farmers' Dwellings Space in Wan'xi Countryside. Anhui Jianzhu University, Hefei. http://kns.cnki.net/KCMS/detail/detail.aspx?dbcode=CMFD\&dbname=CMFD2016 $\underline{01}$

[4] Kain, J.F. (1968) Housing Segregation, Negro Employment, and Metropolitan Decentralization. The Quarterly Journal of Economics, 82, 175-197.

[5] Hochman, O., Fishelson, G. and Pines, D. (1975) Intraurban Spatial Association between Places of Work and Places of Residence. Environment and Planning A, 7, 273-278.

[6] Gin, A. and Sonstelie, J. (1992) The Streetcar and Residential Location in Nineteenth Century Philadelphia. Journal of Urban Economics, 32, 92-107.

[7] Bertaud, A. (2003). World Development Report 2003: Dynamic Development in a Sustainable World Background Paper: The Spatial Organization of Cities Deliberate Outcome or Unforeseen Consequence? World Bank, Washington DC.

[8] Helsley, R. and Sullivan, A. (1991) Urban Subcenter Formation. Regional Science and Urban Economics, 21, 255-275.

[9] Anas, A., Arnott, R. and Small, K. (1998) Urban Spatial Pattern. Journal of Economic Literature, 36, 1426-1464.

https://ideas.repec.org/a/aea/jeclit/v36y1998i3p1426-1464.html

[10] He, H.B. (2005) The Main Theory and Evolution Trend of Western Urban Spatial Structure. Journal of Shanghai Administration Institute, 6, 96-104.

[11] Li, J.H. and Chen, Y. (2012) Ecological Wisdom and Redesign of Jiarong Tibetan Residence in Western Sichuan. Journal of Xi'an University of Architecture and Technology (Nature Science Edition), 44, 512-516.

[12] Jiang, Y. (2008) Study on the Traditional Tibetan Settlements in Danba, Sichuan Province. Chongqing University, Chongqing.

http://kns.cnki.net/KCMS/detail/detail.aspx?dbcode=CMFD\&dbname=CMFD2009 \&filename $=2009046873 . \mathrm{nh}$

[13] Wang, M.D. (2016) Study on the Traditional Tibetan Settlement and Vernacular Architecture of Jiarong Based on Digital Technology. Xi'an University of Architecture and Technology, Xi'an.

http://kns.cnki.net/KCMS/detail/detail.aspx?dbcode=CMFD\&dbname=CMFD2017 01\&filename $=1016740974 . \mathrm{nh}$

[14] Wang, C. (2014) Study on Jiarong Traditional Tibetan Settlements and Local-Style 
Dwelling Houses Based on Phenomenological Perspective. Xi'an University of Architecture and Technology, Xi'an.

http://kns.cnki.net/KCMS/detail/detail.aspx?dbcode=CMFD\&dbname=CMFD2015 $\underline{02 \& \text { filename }=1015036486 . \mathrm{nh}}$

[15] Xie, J. (2010) Study on the Traditional Tibetan Residential of Ganzi Areas in Southeastern Sichuan. Xi'an University of Architecture and Technology, Xi'an.

http://kns.cnki.net/KCMS/detail/detail.aspx?FileName=2010134666.nh\&DbName= CMFD2010

[16] Liu, X. (2015) Study on Architectural Morphology and Ecological Performance of the Jiarong Tibetan Vernacular Dwellings in Northwest Sichuan. Xi'an University of Architecture and Technology, Xi'an.

http://www.cnki.net/kcms/detail/detail.aspx?dbname=CMFDTEMP\&filename $=101$ 5994508.nh

[17] Liu, X., Li, J.H. and Du, G.C. (2015) Ecological Characteristics of Jiarong Tibetan Vernacular Dwellings in Northwest Sichuan. Building Energy Efficiency, 43, $74-77+92$.

[18] Zhang, Y. (2012) Study on the Jiarong Tibetan Vernacular Dwellings of Sha'erzong in West-Sichuan. Xi'an University of Architecture and Technology, Xi'an.

http://www.cnki.net/kcms/detail/detail.aspx?dbname=CMFD2013\&filename $=10120$ 45688.nh

[19] Zhao, L. (2014). Study on the Traditional Tibetan Residential Construction Mode of Jiarong in West Sichuan. Xi'an University of Architecture and Technology, Xi'an. http://kns.cnki.net/KCMS/detail/detail.aspx?dbcode=CMFD\&dbname=CMFD2015 $\underline{02 \& \text { filename }=1015036762 . \mathrm{nh}}$

[20] Wei, J. (2017) Research on Traditional Construction Methods of Danba Traditional Residence. Journal of Southwest Minzu University (Natural Science Edition), 43, 431-440.

[21] Wang, Y. (2014) Research of Update Design of Jiarong Tibetan Dwelling. Xi'an University of Architecture and Technology, Xi'an.

http://kns.cnki.net/KCMS/detail/detail.aspx?dbcode=CMFD\&dbname=CMFD2015 $\underline{02 \& \text { filename }=1015036427 . \mathrm{nh}}$

[22] Cui, W.H., Wang, J. and Yue, B.R. (2012) Study on the Renewal Model of Traditional Dwellings inhabited by Multinationals. Architectural Journal, 11, 83-87.

[23] Che, X.M. (2015) Renewal Research on Interior Spatial Form of Traditional Residence in Huizhou. Xi'an University of Architecture and Technology, Xi'an. http://kns.cnki.net/KCMS/detail/detail.aspx?dbcode=CMFD\&dbname=CMFD2016 $\underline{01 \& \text { filename }=1015995737 . \mathrm{nh}}$

[24] Cheng, B., Xiao, Y. and Gao, M. (2017) Study on Seismic Construction Design of Traditional Tibetan and Qiang's Stone Dwellings in Western Region of Sichuan Province. Low Temperature Architecture Technology, 09, 44-47.

[25] Jacobs, J. (1993) The Death and Life of Great American Cities. Random House, New York.

[26] He, Q., Lv, X.H. and Liu, J.P. (2011) Tibetan Dwellings in the Process of Urbanization. Electric Technology and Civil Engineering (ICETCE), 2011 International Conference, Lushan, 22-24 April 2011, 3739-3741.

[27] Chen, Y., Cheng, B. and Gao, M. (2017) Investigation of Jiarong Tibetan Stone Dwelling in Danba. City \& House, No. 03, 51-54.

[28] Lang, W.W. and Zhou, Y.J. (2015) The Religious Culture about Jiarong Tibetan Nationality of Village Community: From Shen Village of Dadu River. Tibetan Studies, 
No. $03,74-80$.

[29] The People's Government of Sichuan Province (2017) Measures for the Management of Rural Housing Construction in Sichuan Province.

http://jiuban.moa.gov.cn/zwllm/zcfg/dffg/201702/t20170214_5475097.html 